\title{
Rhodesian Ridgeback
}

National Cancer Institute

\section{Source}

National Cancer Institute. Rhodesian Ridgeback. NCI Thesaurus. Code C53910.

The Rhodesian Ridgeback is a large, muscular hound. Its most unique characteristic is a clearly defined symmetrical ridge running the length of its back, formed by hair that grows in the opposite direction from the rest of its coat. The short, sleek coat comes in light to dark wheaten, sometimes with small white markings on the chest and feet. Height: 24-27 inches (61-69 cm.) Weight: 65-90 pounds (29-41 kg.) 